\title{
CONTABILIDADE: ATUAIS DESAFIOS E ALTERNATIVA PARA SEU MELHOR DESEMPENHO*
}

\author{
NATAN SZÜSTER \\ Professor Titular da UFRJ - RJ \\ Professor Adjunto da UERJ - RJ \\ E-mail: natan.szuster@terra.com.br \\ FORTUNÉE RECHTMAN SZÜSTER \\ Professora Ms. da Fundação Getúlio Vargas - RJ \\ E-mail: frszuster@terra.com.br
}

\section{RESUMO}

O presente trabalho objetiva efetuar uma reflexão sobre os atuais desafios encontrados pelos profissionais da contabilidade do Brasil para evidenciar uma Demonstração Contábil que retrate a realidade das empresas e apresentar uma proposta para ampliar a capacidade informativa das Demonstrações Contábeis.

No mundo atual faz-se necessário que a informação Contábil possua qualidade e credibilidade. Entretanto, a crescente complexidade das atividades empresariais e determinadas restrições tributárias nos fazem deparar com críticas fundamentadas quanto à necessidade de seu aprimoramento. Paralela à analise das dificuldades existentes, é colocada a extrema dificuldade de mudanças substanciais na atual normatização contábil.

Visando propiciar um aperfeiçoamento mais imediato da contabilidade é proposta a apresentação, de forma voluntária, de uma nova informação contábil denominada "Demonstração do Patrimônio Líquido Efetivo". Essa parte do Patrimônio Líquido Societário efetua ajustes visando evidenciar um valor mais realista dos ativos e dos passivos.

A análise da relação custo $\times$ benefício dessa nova Demonstração é efetuada concluindo-se que essa informação adicional poderá constituir-se em uma grande evolução, aprimorando o atual produto gerado pela contabilidade brasileira com um custo reduzido. A sua aplicação poderá ser um fator diferencial para uma empresa que divulga as Demonstrações Contábeis para os usuários externos e poderá ser também de grande utilidade para ampliar a capacidade informativa de todos os usuários internos.

Palavras-Chave: Patrimônio Líquido Efetivo; Contabilidade Financeira; Informação Contábil.

\author{
FLÁVIA RECHTMAN SZÜSTER \\ Mestranda pela COPPEAD-UFRJ - RJ \\ E-mail: fszuster@coppead.ufrg.br
}

\section{ABSTRACT}

This paper aims to debate the current challenges Brazilian accountants face when trying to disclose, through the financial statements, what is really happening in their companies. Furthermore, a proposal is presented that aims to improve the informational capacity of accounting in terms of quality.

A world where accounting information does not inspire confidence and credibility is rather unthinkable. Meanwhile, the growing complexity of business activities and some tax restrictions makes us face criticism grounded in the urgent need for improvements in accounting information. At the same time, we must deal with extreme difficulties for making substantial changes in current Accounting regulations.

With a view to a rapid improvement in accounting information, we propose that companies voluntarily present a new statement called "Effective Stockholder Equity Statement". It starts from corporate law values and adjusts assets and liabilities to present the value of stockholder's equity in a more realistic way.

The cost-benefit relation of this new statement is analyzed, leading to the conclusion that it can bring about an important evolution, improving the product presented by Brazilian accounting at a reduced cost. Its application may be a differential factor for companies that disclose financial statements to external users, and can also be highly useful to expand the information capacity of all internal users.

Keywords: Effective Stockholder Equity; Financial Accounting; Accounting Information. 


\section{INTRODUÇÃO}

A Contabilidade é um patrimônio da humanidade. Sua atuação é fundamental para o desenvolvimento e para a própria sobrevivência da sociedade.

Através das informações contábeis são desenvolvidas as relações entre os diversos agentes econômicos, com grande influência na determinação do custo de capital impactando, de forma direta, na riqueza do acionista.

A complexidade do mundo atual tem propiciado o surgimento de problemas de difícil solução para a Contabilidade. Como conseqüência, tem sido criticada por não apresentar informações em quantidade e qualidade desejadas por seus diversos usuários, em especial no que se refere a uma avaliação mais adequada do valor do patrimônio das empresas.

Considerando a necessidade de os profissionais da contabilidade direcionarem sua atuação aos usuários de sua informação, o presente trabalho pretende efetuar uma reflexão sobre os atuais desafios encontrados, apresentando como alternativa uma ampliação das informações complementares às Demonstrações Contábeis divulgadas.

O modelo proposto, idealmente, deveria ser passível de divulgação para os usuários externos, mas as sugestões podem, também, ser utilizadas internamente, principalmente pelas médias e pequenas empresas.

\section{A IMPORTÂNCIA DA CONTABILIDADE}

A Contabilidade nasceu dentro de um cenário absolutamente prático, decorrente da necessidade de informação sobre o lucro do período por parte dos gestores do patrimônio. A base fundamental decorreu do registro dos efeitos das transações entre a entidade e o mundo exterior.

Para avaliar a sua real importância deve-se imaginar como seria o mundo sem a Contabilidade. Certamente haveria uma maior dificuldade para toda a humanidade. Não haveria controle dos recursos públicos e privados além da impossibilidade da avaliação das entidades, influenciando todo o sistema de alocação de recursos.

Como Ciência Social, a Contabilidade é um produto do meio refletindo as diferentes condições sócio-econômico-político-legais. Como conseqüência, para que cumpra sua missão, deve acompanhar as mudanças da sociedade em que está inserida. Nesse início de século, em que o ambiente econômico se apresenta cada dia mais incerto, a Contabilidade deve manter sua postura prudente sem perder a qualidade da evidenciação de suas informações.
As Demonstrações Contábeis constituem a grande plataforma de segurança para todos os agentes econômicos. É importante que haja a percepção da sociedade no que diz respeito à seriedade e à validade da estrutura contábil.

Entretanto, é fundamental que os profissionais da contabilidade sejam proativos procurando sempre alternativas para aperfeiçoamento da capacidade informacional, nunca se afastando do seu grande objetivo de prover seus usuários com demonstrações e análises de natureza econômica, financeira, física, e de produtividade, com relação à entidade objeto de contabilização.

\section{COMO REPRODUZIR A ATUAL REALIDADE}

O mundo atravessa uma fase muito complexa. Um grande avanço tecnológico, propiciado pela informática e a indústria de telecomunicações, permitiu uma grande evolução da ciência, gerando novos bens e serviços. De forma simultânea, observa-se um elevado aumento do risco, decorrente da insegurança crescente, terrorismo e flutuações abruptas no câmbio, nos preços dos insumos de produção e das ações das empresas.

A riqueza da empresa não mais está centrada apenas em bens físicos, mas no Capital Intelectual e em ativos intangíveis próprios de cada setor da Economia.

As mudanças constantes têm gerado um ambiente dinâmico e competitivo, exigindo a cada dia melhores resultados por parte dos administradores. Como conseqüência, em situações em que tal meta não pode ser atingida há o risco de a Contabilidade ser utilizada como um instrumento para gerenciar resultados.

Em relação ao cenário internacional vive-se um momento histórico com a evolução do processo de convergência das normas contábeis, coordenado pelo International Accounting Standards Board (IASB) - Comitê Internacional de Padrões de Contabilidade - podendo representar uma grande revolução para a ciência contábil. Uma das grandes exigências também a nível internacional é a maior transparência das empresas. De acordo com o Presidente da Bolsa de Valores de São Paulo (Bovespa), Raimundo Magliano, em palestra proferida na reunião da United Nations Conference on Trade and Development (Unctad), realizada em São Paulo em 14 de julho de 2004, as empresas precisam ter maior visibilidade para que possam desempenhar seu papel na sociedade.

Diante dos desafios que o momento apresenta, aumenta a responsabilidade do profissional da contabilidade em fornecer informações oportunas e 
com qualidade para todos os seus usuários, apesar de todas as dificuldades existentes.

\section{CRÍTICAS ÀS INFORMAÇÕES CONTÁBEIS}

Diversos profissionais têm apresentado restrições ao atual produto gerado pela Contabilidade, considerando que não está proporcionando as informações necessárias para a sua decisão.

ludícibus e Oliveira (2003) afirmam que é forte a percepção do mercado de que as demonstrações contábeis não representam a realidade da estrutura contábil e financeira das organizações. A avaliação conservadora, baseada no custo original, falha ao utilizar as demonstrações contábeis como elemento preditivo de tendências futuras para os usuários externos.

Assaf e Procópio (2004) afirmam que a postura tradicional da contabilidade, com ênfase no lucro e na rentabilidade, já não atende, em sua plenitude, aos anseios dos usuários.

O Professor Baruch Lev (2000), fundamentado em seus estudos desenvolvidos no Centro de Pesquisa de Ativos Intangíveis da Universidade de New York, ressalta a necessidade do avanço da contabilidade, em especial quanto ao reconhecimento do valor criado pelos Ativos Intangíveis idéias, marcas, maneiras de trabalhar, franquias cujo valor em muitas empresas é superior aos ativos contabilizados. Tal dissociação afeta os analistas e diretores financeiros. Os executivos não possuem dados sólidos para decidir se apóiam ou não determinado projeto.

Bennet Stewart, sócio da Stern \& Stewart, em entrevista à Revista Exame, em 29 de outubro de 2003, declara que a contabilidade não está funcionando visto que os princípios que norteiam os contadores foram adotados há muito tempo, quando os ativos intangíveis não eram muito significativos. Coloca, ainda, que a contabilidade é estruturada do ponto de vista do credor e não dos acionistas, visto que as atuais práticas surgiram quando a principal fonte de capital das empresas eram os Bancos. Como exemplo, cita os gastos em pesquisa e desenvolvimento que nos Estados Unidos são contabilizados como despesa. Tal poderia ser aceito apenas do ponto de vista do credor, uma vez que não há garantia do retorno do que a empresa gasta para desenvolver uma nova tecnologia. O investidor, por sua vez, tem uma visão diferenciada julgando que as ações da empresa irão se valorizar já que os recursos aplicados irão retornar no longo prazo, sob a forma de aumento de produtividade e novos produtos, gerando o aumento dos lucros.

Um grande problema é o fato de a contabilidade brasileira estar sendo realizada, desde
31.12.1995, com base no custo histórico, não reconhecendo, assim, os efeitos da flutuação de preços. A partir dessa data até Dezembro de 2004, os indexadores gerais de preços ou de índices de custo de vida atingiram níveis expressivos que afetaram de modo substancial o valor do patrimônio e do resultado das empresas brasileiras. A variação do IGPM foi de $167 \%$ e o IPCA de $93 \%$. Comparando com o parâmetro de somente obrigar o reconhecimento do efeito da inflação se essa atingir $100 \%$ em 3 anos, verifica-se que a inflação, mesmo em um patamar inferior, afeta de forma decisiva as informações contábeis. Por exemplo, o valor do Patrimônio Líquido da Companhia Vale do Rio Doce, em 31.12.2003, pelo método da Correção Monetária Integral era de $\mathrm{R} \$ 31,2$ bilhões enquanto, de acordo com a legislação societária, era de $R$ \$ 14,9 bilhões. Portanto, há uma diferença de $110 \%$. O lucro líquido na $\mathrm{CMI}$ é de $R \$ 5,5$ bilhões enquanto no Societário é de $R \$$ 4,5 bilhões, o que representa uma diferença também gigantesca afetando todos os indicadores. A rentabilidade do Patrimônio Líquido no método societário é de $30,18 \%$ enquanto na $\mathrm{CMl}$ é de $17,51 \%$. Assim, demonstra-se a grande materialidade do impacto do reconhecimento do efeito inflacionário e a distorção que pode ser causada pela utilização pura dos valores sem correção. A utilização do parâmetro internacional como referência é amplamente questionável.

Segundo o professor Hugo Rocha Braga (2003), a falta de informação contábil em moeda constante é um grande obstáculo para a implantação de sistemas de governança corporativa no momento em que muitos esforços estão sendo desenvolvidos para aprimorar o nosso mercado de capitais.

Outro problema abordado decorre dos efeitos do câmbio flutuante que, com suas variações abruptas e irreais, influencia de forma significativa os resultados das empresas brasileiras. A volatilidade do dólar, nos anos de 2002 e 2003, exerceu um efeito significativo. Em 2002, com grande elevação do dólar comprovadamente por fatores especulativos, empresas com bom desempenho operacional apresentaram prejuízos gerando críticas à contabilidade, que tem que ficar amarrada a contabilizar valores que efetivamente não condizem com a realidade.

Todas essas críticas devem ser visualizadas como motivação para reflexão e análise da qualidade da atuação da contabilidade brasileira, entendendo a necessidade de realizar aprimoramentos.

\section{DIFICULDADES PARA UMA MUDANÇA SUBSTANCIAL}

Um aspecto relevante é entender a enorme dificuldade vivenciada pelos integrantes das entidades 
contábeis normatizadoras. Esses vivenciam grandes dualidades, como a necessidade de definir se devem aumentar o número de normas acompanhando todas as novas operações realizadas pelas empresas ou exercer a regulação baseada em princípios. Ao mesmo tempo, devem definir como equilibrar a postura rígida necessária, sem que haja restrição total sobre a capacidade do profissional da contabilidade em retratar a realidade de acordo com as características da empresa e da transação econômica realizada. E, também, como garantir a aplicação da essência econômica sobre a forma jurídica.

Katherine Schipper, membro do Board do Fasb, Financial Accounting Standards Board - Comitê de Padrões Contábeis dos Estados Unidos, em palestra proferida na $14^{\circ}$. Asian Pacific Conference on International Accounting Issues, em Los Angeles no ano de 2002 coloca a falta de condições para a Contabilidade acompanhar, como necessário, a acentuada evolução da realidade, gerando um grande problema. Ela afirmou ainda, ser impossível normatizar todas as operações efetuadas pela empresa, até porque, diariamente, surgem novas.

Em decorrência da grande complexidade do mundo e do risco da ocorrência de fraudes, observa-se a tendência de a contabilidade se tornar mais conservadora e rígida, diminuindo, assim, a possibilidade de ampliar novas formas mais arrojadas.

Entretanto, o problema é relevante uma vez que o Princípio de Competência de Exercícios, reconhecido como de grande poder informacional por efetuar a alocação lógica e sistemática do fluxo de caixa da empresa durante a sua vida, possui um caráter subjetivo sendo necessárias premissas estabelecidas pelos profissionais.

Contudo, se for permitida uma liberdade muito grande, pode-se perder uma característica fundamental que é a uniformidade. $E$ a tendência atual é a opção pela uniformidade. Como exemplo pode ser citado o atual posicionamento do IASB. No passado, as normas internacionais admitiam tratamentos diferenciados para um mesmo evento. No momento, tenta-se reduzir tais alternativas, privilegiando a uniformidade. Essa linha de rigidez foi seguida pela instituição ao não permitir a utilização da linha "Itens Extraordinários" nas Demonstrações Contábeis. Essa alternativa válida, que possibilitava a separação de itens efetivamente não usuais e infreqüentes, poderia ser aplicada de forma errônea ao retirar do resultado operacional itens que a administração julgava indesejáveis.

Uma dificuldade adicional decorre do amplo uso da contabilidade por outros usuários, especialmente pelo Fisco que inibe a empresa de contabilizar os fatos de acordo com a realidade. Um exem- plo é o processo de depreciação contábil adotado pela maioria das empresas brasileiras que não reconhece o valor residual dos bens e utiliza a menor estimativa de vida útil admitida pelo Fisco.

Outro entrave à melhoria das informações contábeis pode ser exemplificado pelo tratamento da Reavaliação de Bens. Esse dispositivo, contido na Lei 6404 , foi recebido como uma evolução da contabilidade por propiciar a vinculação com a avaliação a valores de mercado. Passados anos de aplicação prática, foi verificado que a sua aplicação gerava distorções, o que estimulou a própria Comissão de Valores Mobiliários a não propor sua manutenção no projeto de mudança da Lei das Sociedades por Ações.

Em 2000, o Professor Eliseu Martins, em entrevista na Revista Exame Digital, sobre a atuação da contabilidade no momento do surgimento da denominada "Nova Economia", afirmou que a contabilidade é fantástica para medir o lucro que aconteceu. Mas é extremamente pobre para medir o futuro. $E$ declara "Como a contabilidade está hoje, está ruim. Mas se mudar piora".

O Professor Baruch Lev (2000) afirma que, apesar das críticas, o sistema contábil não está falido. Esse ainda é incrivelmente eficiente. Fazem-se necessários, porém, ajustes para melhorar o que existe.

Em entrevista à revista Exame no exemplar do dia 17 de março de 2004, o Professor Ariovaldo dos Santos declara que a contabilidade funciona e que as irregularidades nas empresas foram descobertas justamente por meio da análise contábil. Afirma que os princípios contábeis são sólidos, consistentes e mudaram muito pouco ao longo dos anos.

Os Professores Eliseu Martins e Sérgio ludícibus (2004) afirmam que a sociedade utiliza de forma inteligente o produto gerado pela contabilidade ressaltando a consistência dos princípios, normas e práticas consagradas após séculos de sedimentação e experimentação.

Como se pode concluir, apesar das críticas existem posicionamentos muito relevantes para que não sejam efetuadas mudanças radicais na atual normatização da Contabilidade. Após uma análise exaustiva dos diversos efeitos para todos os agentes econômicos deveriam ser realizadas, com muita cautela, as devidas alterações.

A liberdade total iria gerar distorções muito mais danosas à sociedade como um todo.

Nas Demonstrações Contábeis apresentadas para o usuário externo, o processo de normatização faz-se necessário para que haja uma relativa uniformidade. É necessária a percepção da sociedade de que existe uma rigidez, e não uma percepção de que existe um afrouxamento das normas. Portanto, alterar a contabilidade societária no que diz respeito 
à diminuição da prudência, seria muito difícil, apesar da demanda de seus usuários por maior quantidade e qualidade informacional das empresas.

Apesar de a normatização contábil ser imprescindível esta pode, simultaneamente, ser restritiva a necessárias inovações. Todos os esforços possíveis devem ser efetuados para aprimorar os atuais princípios e normas contábeis, mas, enquanto tais alterações não ocorrerem, faz-se necessário manter a qualidade da informação contábil através de evidenciação de Demonstrações Complementares em Notas Explicativas.

\section{APERFEIÇOAMENTO DA CONTABILIDADE}

Para que haja melhoria da informação contábil, sem alterações substanciais e imediatas em sua normatização, o presente trabalho propõe que seja aprimorada a evidenciação, através da divulgação de informações adicionais.

De forma básica, reitera-se a proposta apresentada nos Estados Unidos por Steve Walman (1995) e no Brasil por Padoveze e Benedicto (2003) no sentido da utilização efetiva de mais de uma Demonstração Contábil. O entendimento é que a Contabilidade em uma única dimensão não é mais suficiente.

Wallman publicou dois artigos (1995 e 1996), comentando a impossibilidade de o Balanço Patrimonial atender aos objetivos de todos os usuários. Assim, propõe que a evidenciação das Demonstrações Contábeis seja realizada em camadas ou etapas partindo das demonstrações contábeis e incluindo diversos itens como os Ativos Intangíveis e mensurações de potenciais ativos. Wallman utiliza a expressão colorir a informação contábil, pois considera que a atual está sendo apresentada em preto e branco, o que distorce a realidade.
Já Padoveze e Benedicto, na sua proposta, partem da Demonstração Contábil atual, de acordo com os princípios contábeis, e sugerem a inclusão de mais três colunas no Balanço e na Demonstração do Resultado. As três colunas adicionais serão efetuadas pelos seguintes critérios de avaliação:

a) avaliação a preço de mercado dos ativos e passivos avaliados individualmente;

b) avaliação a preço de mercado acionário e

c) avaliação considerando os fluxos futuros de benefícios, descontados pelo custo de oportunidade do capital.

Essas propostas têm como objetivo comum permitir aos profissionais de contabilidade, atender a todas as normatizações oficiais e também apresentar informações complementares que melhor evidenciem a realidade da empresa. A aplicação da visão justa e verdadeira, segundo os profissionais da contabilidade, seria possível, propiciando maior transparência.

\section{PROPOSTA DE UMA NOVA DEMONSTRAÇÃO CONTÁBIL: "DEMONSTRACCÃO DO PATRIMÔNIO LÍQUIDO EFETIVO"}

A Demonstração proposta no presente trabalho parte do conceito do Patrimônio Líquido oficial, ajustando os valores dos Ativos e Passivos com a grande possibilidade de incluir novos itens a esses elementos. A classificação deve estar pautada de forma exclusiva nas definições conceituais de Ativos e Passivos incorporando os mais avançados métodos de mensuração já desenvolvidos pela Contabilidade.

A seguir, serão apresentados alguns exemplos de itens que podem ser considerados para que seja evidenciado um valor do Patrimônio Líquido mais real.

\section{DEMONSTRAÇÃO DO PATRIMÔNIO LíQUIDO EFETIVO}

PATRIMÔNIO LíQUIDO SOCIETÁRIO
(+/-) AJUSTES DOS ATIVOS
a) Atualização monetária dos ativos não-monetários e ajuste a Valor presente dos ativos prefixados.
b) Reconhecimento do valor de mercado de ativos financeiros e não monetários, ajustando também o efeito da utilização da
taxa de fechamento do dólar quando distorcida.
c) Ativos Intangíveis não contabilizados.
d) Ajuste de contas retificadoras de ativos.
e) Inclusão de Direitos não reconhecidos em virtude do Princípio da Prudência.
f) Ajustes de Valores considerados com Capacidade de Benefícios futuros, mas reconhecidos no resultado.




\section{PATRIMÔNIO LÍQUIDO SOCIETÁRIO}

\section{(+/-) AJUSTES DOS PASSIVOS}

a) Reconhecimento da atualização monetária dos Passivos não-monetários e ajuste a Valor Presente dos passivos prefixados.

b) Ajuste ao Valor de Mercado dos Passivos, reconhecendo ajustes decorrentes da utilização da taxa de fechamento do dólar quando distorcida.

c) Complementação de Passivos não contabilizados de forma completa.

d) Reconhecimento dos "Passivos fora do Balanço" (Off-Balance-Sheet Liabilities).

e) Reconhecimento de Contingências não provisionadas.

= TOTAL DO PATRIMÔNIO LÍQUIDO EFETIVO

A seguir, serão apresentados alguns comentários sobre os diversos itens acima expostos.

O objetivo é apresentar idéias a serem ampliadas por todos os profissionais da contabilidade. Ressalte-se que a inclusão deverá ser efetuada para os itens de valor significativo.

\subsection{Ajustes dos Ativos}

a) Reconhecimento dos efeitos inflacionários: Um aspecto fundamental diz respeito à avaliação em moeda constante, incluindo o conceito do Valor Presente dos recebíveis, retirando os juros embutidos nesses elementos. Conforme já comentado no caso da Companhia Vale do Rio Doce, um ajuste dessa categoria poderia duplicar o valor do Patrimônio Líquido. É muito provável que impactos significativos ocorram em muitas outras empresas brasileiras.

b) Reconhecimento do Valor de mercado dos Ativos:

Após a avaliação dos ativos em moeda constante, deverá ser reconhecido o Valor de mercado dos ativos complementando ou diminuindo o valor histórico corrigido. A empresa poderia adotar os conceitos de Valor de entrada ou Valor de Saída considerando a intenção de uso do ativo. Os itens Instrumentos Financeiros, Estoques, Ativos Imobilizados e Investimentos avaliados ao Custo e pelo Método da Equivalência Patrimonial poderiam, por exemplo, ser ajustados.

A mensuração dos Estoques poderia contemplar as mercadorias fungíveis das empresas mineradoras, petrolíferas, agrícolas e pecuárias, cujo valor de mercado, normalmente, não é reconhecido em virtude do efeito tributário, apesar de previsto na legislação societária.

Os Instrumentos Financeiros em moeda estrangeira poderiam ser ajustados, depois de considerada a intenção de realização, caso a taxa do dólar, nessa data, seja considerada distorcida, de acordo com a Teoria da Paridade Cambial ou outra Teoria reconhecida pelos usuários.

c) Ativos Intangíveis:

A empresa poderia evidenciar os Ativos Intangíveis mais significativos e que não estão contabilizados, mas são considerados integrantes do patrimônio efetivo da empresa. No caso, o conceito do método do Fluxo de Caixa Descontado poderia ser utilizado. A forma de classificação poderia utilizar como referência a proposta desenvolvida pelo FASB, destacando, por exemplo, Intangíveis relativos a fatores de mercado (Carteira de Clientes), Direitos Contratuais, Ativos relacionados a inovações tecnológicas, e Ativos relativos à estrutura da empresa, incluindo o valor da própria Marca desenvolvida e o Capital Intelectual. Esse tipo de informação é apontado por Baruch Lev (2004) como de grande importância, quando nem a empresa, nem o mercado avaliam corretamente o investimento em Ativos Intangíveis, inviabilizando uma correta alocação de recursos.

d) Ajuste de contas retificadoras de ativos não reconhecidas de forma adequada:

Nesse item, podem ser ajustados os ativos depreciados ou amortizados de forma acelerada que não retratem a realidade como é o caso, via de regra, das edificações, depreciadas em 25 anos. 
O ajuste deveria utilizar uma taxa realista até mesmo para sinalizar ao mercado por quanto tempo a empresa espera utilizar o ativo, a possibilidade de sua recuperação, assim como quando será necessária sua reposição.

O mesmo raciocínio poderia ser aplicado para a amortização do Ágio por Rentabilidade Futura quando a empresa considera que os benefícios sejam superiores aos 10 anos estabelecidos pela CVM.

O Ajuste pode abranger a constituição de uma Provisão para Créditos de Liquidação Duvidosa de forma realista considerando o efetivo risco de crédito. A quantificação real de diversas Provisões redutoras do ativo poderia ser avaliada incluindo a Provisão para Passivo a Descoberto, calculada através de conceitos estatísticos.

e) Direitos não reconhecidos devido às restrições do Conservadorismo:

A empresa poderia evidenciar Direitos com potenciais benefícios futuros que não são contabilizados devido à restrição da contabilidade como no caso dos Créditos Fiscais, principalmente decorrentes de Prejuízos Fiscais e Ativos Contingentes. Um cálculo probabilístico deveria ser aplicado.

f) Valores reconhecidos no resultado por imposição das atuais normas:

Esse ajuste poderia incluir gastos que a empresa considera que irão gerar benefícios futuros como os incorridos na fase inicial da empresa com Pesquisas e Desenvolvimento não diferidos, com Propaganda e Treinamento, contabilizados de forma imediata como despesa.

Em relação a todos os itens do ativo deveria ser efetuado um teste para analisar a capacidade de realização, conhecido internacionalmente como Teste de Impairment; os valores apresentados nunca devem superar os benefícios futuros esperados.

\subsection{Ajustes dos Passivos}

Para que as Demonstrações contábeis sejam justas é fundamental que os Passivos apresentem o valor mais aproximadamente possível dos Sacrifícios Futuros de Caixa derivados de transações ou eventos passados.

a) Reconhecimento da atualização monetária dos Passivos não-monetários e ajuste a Valor Presente dos passivos prefixados:

$O$ efeito da inflação deve ser reconhecido sobre os Passivos não Monetários, como os Adiantamentos de Clientes que podem estar apresentando valores subavaliados. Em empresas que assumem Passivos prefixados ou compram a prazo de Fornecedores com valores estipulados em reais fixos, os valores devem ser descontados considerando o poder de compra projetado para a efetiva data do pagamento.

b) Ajuste ao Valor de Mercado dos Passivos e reconhecimento de ajustes decorrentes da utilização da taxa de fechamento do dólar, para os Passivos de Longo Prazo:

Esse ajuste pode ser aplicado para empresas que emitiram debêntures e outros instrumentos de dívida que são negociados no Mercado Secundário. A aplicação deve considerar a intenção da empresa e sua possibilidade de resgatar ou transacionar com esses títulos. Para empresas que têm dívidas em moeda estrangeira com vencimento a longo prazo, quando o dólar estiver defasado, ela poderia realizar o ajuste considerando a avaliação do dólar de acordo com métodos desenvolvidos pela ciência econômica.

c) Complementação de Passivos não contabilizados completamente como desembolsos de Benefícios após Aposentadoria dos seus empregados:

Um dos Passivos mais relevantes para empresas que possuem planos de benefício definido são os gastos que a empresa terá após seus empregados se aposentarem, abrangendo complementação de aposentadoria e cobertura de gastos com saúde. Tanto a contabilidade internacional quanto a brasileira possuem regras que não obrigam a contabilização do Passivo por um valor máximo. Desse modo, a empresa pode estar cumprindo a normatização e não apresentar um valor do Passivo que exprima o desembolso de caixa futuro. A empresa deve avaliar sempre qual a sua situação, complementando sua obrigação sempre que essa não tiver sido feita Adequadamente.

d) Reconhecimento dos denominados OffBalance-Sheet Liabilities: 
Em diversas situações as empresas efetuam operações estruturadas sem a obrigatoriedade, pela atual legislação societária, de evidenciação do Passivo total. Como exemplo pode-se citar as operações de Arrendamento Mercantil e as que envolvem Sociedades de Propósito Específico. Quando tal ocorre as empresas deveriam efetuar o ajuste objetivando que o efetivo endividamento seja divulgado.

e) Contingências possíveis e remotas:

As normas contábeis somente obrigam o registro contábil da Contingência quando essa é tida como provável. Nessa Demonstração, a empresa poderá efetuar o complemento do valor já provisionado, reconhecendo as contingências possíveis e remotas, incluindo Passivos relacionados ao meio-ambiente. Nesse caso, deve ser aplicado um cálculo probabilístico.

O valor ajustado do Passivo poderá assegurar ao usuário que inexistem Passivos omitidos, ao mesmo tempo que protege a empresa contra possíveis reclamações ao não divulgar, em suas Demonstrações Contábeis, de forma completa, os prováveis desembolsos futuros.

\section{CONSIDERACCÕES SOBRE A DEMONSTRACCÃO DO VALOR DO PATRIMÔNIO ĹÍQUIDO EFETIVO}

$\mathrm{Na}$ proposta apresentada não se pretende quantificar o valor da empresa em uma hipótese de venda, pois essa decisão envolve diversos outros fatores, não se constituindo o objetivo da contabilidade. Em sua essência, a proposta visa a uma melhoria no aspecto informacional da Contabilidade, atendendo a sua essência utilitária. Sem dúvida, essa Demonstração do Patrimônio Líquido Efetivo pode reduzir o atual distanciamento entre o valor das empresas, negociado em uma transação com terceiros ou calculada por algum método de avaliação, e o valor patrimonial apresentado pela contabilidade societária.

Nessa evidenciação, deve ser aplicado o conceito introduzido pelo professor Sérgio de ludícibus de Subjetividade Responsável em contrapartida à definição do professor Nelson Carvalho da atual realidade como Objetividade Cega. A aplicação dessa proposta pode tornar transparentes diversos itens cujo registro contábil oficial tem gerado grande controvérsia, como, por exemplo, o ativo referente ao direito de concessão pago pelas concessioná- rias de serviços públicos. Um setor econômico cuja contabilização é muito complexa, como o dos clubes de futebol poderá apresentar uma grande evolução no que se refere ao tratamento contábil dos gastos para formação de atletas e reconhecimento do valor de mercado dos direitos federativos dos atletas profissionais, visto que no Brasil tais itens constituem o principal patrimônio de um clube, mas a contabilização tem gerado grande polêmica.

O modelo completo e a periodicidade devem ser estabelecidos a critério da empresa. A aplicação prática poderá propiciar uma experiência para seu constante aprimoramento. O modelo poderá evoluir e a empresa poderá apresentar não apenas o Patrimônio Líquido ajustado, mas evidenciar o próprio Balanço Patrimonial de forma completa. $O$ fato de a demonstração ser elaborada de acordo com a sistemática de Inventário, pode facilitar a sua elaboração. Em termos de prazo, quanto mais freqüente, melhor seria a informação para o usuário.

Uma possibilidade suplementar para os diversos usuários da Contabilidade é analisar o cálculo da variação entre os dois montantes do Patrimônio Líquido da empresa em diferentes períodos. Esse parâmetro pode constituir uma informação adicional de grande utilidade, aprimorando o cálculo do valor do Goodwill. O cálculo deve ponderar as demais mutações do Patrimônio Líquido, consideradas em moeda de poder aquisitivo constante. O conceito de custo de oportunidade deveria, também, ser utilizado. Desse modo, a efetiva riqueza gerada pela empresa em um determinado período, poderia estar sendo medida com maior adequacidade, de forma periódica.

Os critérios de avaliação dos ativos devem ser definidos considerando a intenção no seu uso. Os métodos de Valores de Entrada e Saída podem ser aplicados. A utilização de parâmetros objetivos, com menor custo deveria ser realizada admitindo a manutenção da qualidade. A utilização de tabelas de preços e cotações de mercado abrangendo transações realizadas divulgadas por entidades especializadas e pela imprensa deveria ser prioritária. Como alternativas para a obtenção dos valores de mercado poderiam ser utilizados valores negociados de transações de empresas equivalentes ou até concorrentes, pesquisas baseadas em parâmetros físicos como, por exemplo, o valor da metragem para imóveis e também avaliação por peritos e especialistas. A Internet poderá se constituir uma grande fonte de obtenção dos dados.

Uma importante experiência refere-se à avaliação dos Passivos a valor de mercado. Esse tema, ainda pouco explorado pela teoria contábil, pode gerar um enfoque relevante para avaliação de uma 
empresa financiada com instrumentos de dívida negociados no mercado.

Um aspecto central é a credibilidade dos valores apresentados. De modo ideal, essa Demonstração deve ser passível de ser submetida a uma firma de auditoria independente, inclusive para controle das contrapartidas.

Apesar de tal evidenciação poder ser realizada até mesmo no Relatório da Administração, acreditase que a força da Demonstração Contábil complementar possa ser superior, uma vez que irá caracterizar uma informação mais estruturada, quantitativa além de mais metódica. A contabilidade oficial poderá se beneficiar com a experiência adquirida nessa Demonstração opcional.

\section{ANÁLISE DA RELAÇÃO CUSTO $\times$ BENEFÍCIO}

Um aspecto relevante a ser ponderado é haver a consciência de que os benefícios da evidenciação para as empresas irão superar os respectivos custos. O principal benefício consiste no aumento da reputação da empresa com uma avaliação mais transparente de seu verdadeiro patrimônio. A conscientização do mercado investidor será um item fundamental, pois esse será o grande validador da proposta.

Um ponto importante refere-se ao fato de que se têm, no Brasil, experiências muito positivas de informação opcional. Um marco histórico foi a evidenciação realizada pela VASP, em 1985 apresentando suas Demonstrações Contábeis de 1983 e 1984 de acordo com o Método da Correção Monetária Integral. No ano seguinte, muitas empresas seguiram esse exemplo, muito antes da obrigatoriedade para as companhias abertas que ocorreu com a Instrução CVM 64 de 19.05.1987.

Além disso, uma grande quantidade de empresas brasileiras evidencia, por iniciativa própria, diversas informações opcionais, como a Demonstração do Valor Adicionado, Balanço Social, a Demonstração dos Fluxos de Caixa e Informações por Segmento de Negócios, sem que haja nenhum requerimento legal.

Um fator relevante positivo decorre da redução de processamento da informação pela informática além do menor custo de divulgação que poderia ser realizada através da Internet.

Apesar de ser responsabilidade de cada empresa o confronto entre custo e benefício, considera-se que os benefícios poderão ser muito superiores ao custo. A empresa poderá utilizar essa Demonstração como uma forma de melhor comunicação com todo o mercado. Algumas críticas poderiam surgir quanto a ser prejudicial uma maior exposição da empresa. Vários exemplos anteriores em que empresas foram pioneiras em divulgações complementares, indicam que o mercado julga meIhor uma empresa transparente do que uma empresa que não revela suas informações. Considera-se, assim, que o segredo pela ausência de informações cria o medo, aumenta o risco e em conseqüência o custo do capital ao afastar credores e investidores.

Para os profissionais da contabilidade que preparam Demonstrações Contábeis, essa nova Demonstração poderá ampliar o seu foco de atuação, inclusive aproximando-os mais da administração. Desse modo, poder-se-á deixar de concentrar de forma exclusiva na normatização oficial para procurar formas diferenciadas de retratar a realidade. Como exemplo, tem-se a evidenciação dos Ativos Intangíveis formados pela empresa e dos Ativos Contingentes. Na prática, não há um debate mais aprofundado desses elementos, uma vez que o profissional da contabilidade e os auditores têm que utilizar a Prudência como referencial básico. No caso proposto, como pode ser efetuada uma estimativa pela empresa para reconhecimento, a análise do fato deverá ser muito mais ampla, havendo um aumento da possibilidade de que sejam exercidos julgamentos mais técnicos.

Para os administradores, a elaboração dessa Demonstração poderá ser mais útil, pois eles, muitas vezes, tomam decisões que acreditam irão gerar benefícios futuros, mas que são reconhecidos pela contabilidade como despesa, diminuindo o resultado do período. Portanto, essa Demonstração poderá propiciar um maior alinhamento da evidenciação contábil com a estratégia das organizações. Esse diálogo poderá propiciar um aumento da valorização da Contabilidade e do profissional.

Ainda, haverá maior qualidade de informação disponível para todos os usuários, e a possibilidade de efetuar análises mais aprofundadas. Uma informação adicional será sobre o efetivo investimento da empresa no Ativo Intangível e no fortalecimento da Marca. Esse aspecto abrange, também, os investidores em caso de compra de ações ou debêntures, instituições financeiras que concedem crédito e as agências de rating. Os acionistas minoritários das companhias abertas serão, portanto, grandes beneficiários.

Desse modo, haverá uma redução da incerteza, uma vez que o nível de assimetria informacional que existe entre a empresa e o usuário irá diminuir, o que poderá beneficiar a todos.

A Demonstração do Patrimônio Líquido Efetivo poderá ser muito útil para a valorização da empresa, considerando o enfoque de Young e O'Byrne. Esses argumentam que "neste novo mundo não basta que 
as empresas sejam competitivas nos mercados comerciais. Elas também devem ser competitivas nos mercados de capitais". Conforme Assaf Neto (2003), "as empresas para sobreviverem precisam apurar direcionadores competitivos, tornando-se atraentes para os investidores e valorizadas pelo mercado". O aumento da qualidade informacional proporcionada por essa informação adicional poderá muito contribuir para a melhor visibilidade da empresa.

\section{CONSIDERAÇÕES FINAIS}

Este trabalho visa contribuir para o aprimoramento da Governança Corporativa na busca de um ambiente de negociação que estimule, ao mesmo tempo, o interesse dos investidores e a valorização das companhias. Sua boa prática tem valor para os investidores, através da qualidade das informações prestadas que reduzem as incertezas no processo de avaliação e, conseqüentemente, o risco.

Os profissionais da Contabilidade no Brasil enfrentam dificuldades no exercício de suas funções. O cumprimento das atuais normas e princípios contábeis não garante evidenciar o retrato fidedigno da situação das empresas. O patrimônio mensurado a valores históricos com uma alta inflação acumulada não reconhecida, a impossibilidade do amplo reconhecimento do valor de mercado, a obrigatoriedade da atualização dos ativos e passivos de longo prazo em moeda estrangeira quando existe entendimento de que os indicadores estão distorcidos, constituem grandes limitações, assim como a impossibilidade do reconhecimento dos Ativos Intangíveis. Outro aspecto relevante é a grande diferença quanto ao valor da empresa sob avaliação gerencial e societária, gerando assimetria de informações aos usuários, em especial aos acionistas minoritários.

A complexidade do mundo demanda maior qualidade das informações contábeis, para que essas mantenham sua credibilidade e utilidade. As diversas fraudes, utilizando a contabilidade, deram origem a uma crescente necessidade de transparência.

A dificuldade de sua evolução, porém, está vinculada à prudência que se tornou ainda mais fundamental após os escândalos ocorridos no início do século nos Estados Unidos. A proposta deste trabaIho é a ampliação do debate sobre as normas vigentes, explicitando os atuais desafios e apresentando uma nova informação denominada: Demonstração do Patrimônio Líquido Efetivo da empresa. Partindo do valor, de acordo com a legislação societária são efetuados ajustamentos utilizando os conceitos mais avançados já desenvolvidos, o que possibilita uma informação mais completa e real.

O profissional da Contabilidade deve coordenar a sua preparação, considerando como fator fundamental a evidenciação mais fidedigna de sua empresa, utilizando a extraordinária estrutura e o imenso potencial informativo dessa ciência. Sua atuação deve ser sempre pautada na Ética e responsabilidade, procurando agregar valor através do aumento da qualidade da informação. Essa Demonstração deveria, também, ser divulgada pelas sociedades por ações para os usuários externos, pois o segredo decorrente da falta de informação gera o medo, aumenta o risco e, em conseqüência, o custo do capital, além de afastar credores e investidores. A Demonstração do Patrimônio Líquido efetivo também poderia ser utilizada de forma gerencial pelas demais empresas, independente do porte, constituindo mais um produto da Contabilidade.

O objetivo deste trabalho é o de provocar um debate sobre a necessidade de aprimoramento visto a Contabilidade estar diante de uma ameaça. Caso não consiga satisfazer o usuário com informações úteis, confiáveis e oportunas, outros profissionais poderão fazê-lo. A Demonstração do Patrimônio Líquido Efetivo sinaliza a possibilidade de uma evolução contínua e segura da Contabilidade.

\section{REFERÊNCIAS BIBLIOGRÁFICAS}

ANTHONY, Robert N.. Rethinking the Rules of Financial Accounting USA: McGraw-Hill, 2004.

ASSAF NETO, Alexandre. Contribuição ao estudo da avaliação de empresas no Brasil: uma aplicação prática. Tese de livre-docência, Faculdade de Economia, Administração e Contabilidade de Ribeirão Preto, USP, 2003.

ARAÚJO, Adriana Procópio de. Contabilidade aplicada à gestão baseada em valor, Revista Brasileira de Contabilidade, 146, mar/abr 2004, p. 3-33.
BRAGA, Hugo Rocha. Balanço contábil de 2002: realidade ou ficção? Revista Pensar Contábil, Conselho Regional de Contabilidade, Rio de Janeiro, n. 9, fev/abr 2003, p. 2-3.

CATELLI, Armando (coordenador). Controladoria: uma abordagem de gestão econômica - GECON, FIPECAFI, $2^{\text {a }}$ ed. ão Paulo: Atlas,2001.

HENDRIKSEN, Eldon S. e BREDA, Michael F. Van.. Teoria da Contabilidade. São Paulo: Atlas, 1999. 
IUDíCIBUS, Sérgio; MARTINS, Eliseu; GELBCKE, Ernesto Rubens. Manual de contabilidade das sociedades por ações: aplicável também às demais sociedades. $6^{\mathrm{a}}$. ed. São Paulo: Atlas, 2003.

2000.

Teoria da Contabilidade. $6^{a}$ ed. São Paulo: Atlas,

Conhecimento, Ciência, Metodologias Científicas e Contabilidade. Revista Brasileira de Contabilidade, n. 104.

; CARVALHO, Nelson. Por que devemos ousar em Contabilidade. Boletim do IBRACON, Maio 2001, p. 1-11.

; OLIVEIRA, Alexandre. Por uma nova estrutura conceitual básica da contabilidade. Boletim do IBRACON, Novembro 2003, p. 1-14.

LEV, Baruch. Afiando os Intangíveis. Harvard Business Review, junho, 2004.

A matemática da nova economia. HSM Management 20 maio-junho 2000 p. 34-40.

MARTINS, Eliseu; IUDíCIBUS, Sérgio de. A Contabilidade não funciona? Revista de Contabilidade, Conselho Regional de Contabilidade, São Paulo, Março 2004, p. 38-45.

O futuro do contador está nas suas próprias mãos. Revista Brasileira de Contabilidade, Dezembro de 1993, p. 110113.

De Luca Paciolo à volta da Contabilidade Gerencial. Boletim IOB Temática Contábil, n. 25,1988.

Que Sorte: A Contabilidade não é uma ciência exata. Boletim IOB Temática Contábil, n. 11, 1992.
PAVODEZE, Clóvis Luís; BENEDICTO, Gildeon Carvalho. Demonstrações Contábeis: proposta de adequação às necessidades dos usuários externos. Boletim do IBRACON. Set/ dez 2002 p. 8-18.

SANTOS, Ariovaldo dos. Reconhecimento da inflação nas Demonstrações Contábeis: infelizmente, uma lição ainda não apreendida por muitos. Boletim do IBRACON. Out/nov, 1998. p. $1-9$.

STICKNEY, Clyde P.; WEIL, Roman L.. Financial Accounting. 9o ed. USA: Thomson Learning, 2000.

SZUSTER, Natan; SZUSTER, Fortunée. Tratamento contábil do câmbio flutuante no Brasil: uma proposta considerando a grande volatilidade 2001/2002. Revista de Contabilidade \& Finanças, USP, n. 31, an/abril, 2003, p. 109-118.

WALLMAN, Steven H.. The future of accounting and disclosure in an evolving world: The need for dramatic change. Accounting Horizons, setembro de 1995, p. 81-91.

The future of accounting financial reporting, part II: the colorized approach. Accounting Horizons, junho de 1996, p. 38-148.

WERNKE, Rodney. Considerações acerca dos métodos de avaliação do capital intelectual. Revista Brasileira de Contabilidade. Ano XXXI. №. 137, set/out 2002, p. 23-38.

YOUNG, David S.; O'BYRNE, Stephen F.. EVA e a gestão baseada em valor. Porto Alegre: Bookman, 2003.

NOTA:

Endereço dos autores:

Univ. Fed. do Rio de Janeiro

Av. Brigadeiro Trompowsky s/n.

Ilha do Fundão - RJ

21941-590

Fundação Getúlio Vargas

Praia de Botafogo, 190

Botafogo - RJ

22250-900 